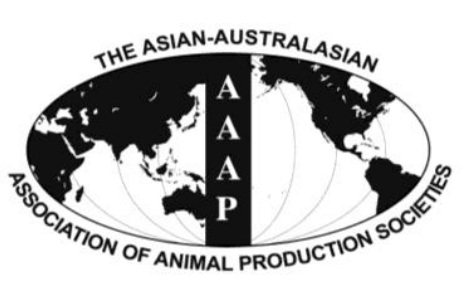

Open Access

Asian Australas. J. Anim. Sci. Vol. 27, No. 10 : 1411-1416 October 2014 http://dx.doi.org/10.5713/ajas.2014.14223

\title{
Determination of Sperm Sex Ratio in Bovine Semen Using Multiplex Real-time Polymerase Chain Reaction
}

\author{
Trisadee Khamlor $^{1,2}$, Petai Pongpiachan ${ }^{2}$, Siwat Sangsritavong ${ }^{1}$, and Nipa Chokesajjawatee ${ }^{1, *}$ \\ ${ }^{1}$ National Center for Genetic Engineering and Biotechnology, \\ National Science and Technology Development Agency, Pathum Thani 12120, Thailand
}

\begin{abstract}
Gender selection is important in livestock industries; for example, female calves are required in the dairy industry. Sexsorted semen is commonly used for the production of calves of the desired gender. However, assessment of the sex ratio of the sorted semen is tedious and expensive. In this study, a rapid, cost effective and reliable method for determining the sex ratio was developed using a multiplex real-time polymerase chain reaction (PCR) assay. In this assay, the X and Y chromosome-specific markers, i.e., bovine proteolipid protein (PLP) gene and sex-determining region Y (SRY) were simultaneously quantified in a single tube. The multiplex realtime PCR assay was shown to have high amplification efficiencies (97\% to 99\%) comparable to the separated-tube simplex real-time PCR assay. The results obtained from both assays were not significantly different $(p>0.05)$. The multiplex assay was validated using reference DNA of known X ratio $(10 \%, 50 \%$, and $90 \%)$ as templates. The measured $\% \mathrm{X}$ in semen samples were the same within $95 \%$ confidence intervals as the expected values, i.e., $>90 \%$ in X-sorted semen, $<10 \%$ in Y-sorted semen and close to $50 \%$ in the unsorted semen. The multiplex real-time PCR assay as shown in this study can thus be used to assess purity of sex-sorted semen. (Key Words: Sperm Sex Ratio, Sex Determination, Sexed Semen, Multiplex Real-time polymerase chain reaction)
\end{abstract}

\section{INTRODUCTION}

Sexual pre-selection plays an important economic role in animal production industries. For example, female cattle are required for the dairy industry while males are preferred in the beef cattle industry (Seidel Jr, 2007). Sorting of $X$ (female) or Y (male) chromosome-bearing spermatozoa in semen is a popular method for sex-selection. Several techniques for sperm sorting technology have been developed; for example, based on different immunological properties of the sperm (Hendriksen et al., 1993; Blecher et al., 1999; Sang et al., 2011), different swimming ability (Madrid-Bury et al., 2003), differential separation in percoll (Machado et al., 2009) and differential separation in

\footnotetext{
* Corresponding Author: Nipa Chokesajjawatee. Tel: +66-25646700, Fax: +66-2564-6707, E-mail: nipa.cho@ biotec.or.th

2 Department of Animal and Aquatic Science, Faculty of Agriculture, Chiang Mai University, Muang District, Chiang Mai 50200, Thailand.

Submitted Mar. 27, 2014; Revised May 19, 2014; Accepted Jun. 1, 2014
}

albumin gradients (Wolf et al., 2008; Machado et al., 2009). Currently, separation of X- and Y- bearing spermatozoa based on differences in their chromosomal content by flow cytometry is considered to be the most reliable and effective method, in which spermatozoa of the desired sex can be obtained in greater than 90\% purity (Morrell et al., 1988; Garner and Seidel Jr, 2003). In order to quantify the purity of sorted semen, flow cytometry reanalysis is usually carried out. However, the accuracy of the estimate of purity is compromised by the systematic error inherent in the technique. Therefore, a different technique should be used to confirm the sex ratio of the flow-sorted semen to reduce the error. Multicolor fluorescent in situ hybridization is considered to be highly reliable method for identifying sex of the spermatozoa, and this method can be used to evaluate the sex ratio of sorted semen (Piumi et al., 2001; Rens et al., 2001; Lee et al., 2004; Habermann et al., 2005). However, this technique is complicated, laborious, time-consuming, and requires highly skilled technicians, which limits its use. Polymerase chain reaction (PCR) techniques for detecting 
DNA sequences on sex chromosomes have been reported which can be used to identify the sex of individual spermatozoa and sex ratios of spermatozoa in semen (Colley et al., 2008; Wang et al., 2011). However, accurate determination of the sex ratio by single-sperm PCR requires analysis of a large number of individual sperm, which is laborious and expensive. In contrast, the sex ratio of semen can be determined accurately and more simply by quantitative real-time PCR (Parati et al., 2006). In this technique, fluorescent labeled-Taqman probes are used to detect DNA sequences on each sex chromosome in two separate reaction tubes, one specific for bovine proteolipid protein (PLP) gene located on the $\mathrm{X}$ chromosome and another for sex-determining region $\mathrm{Y}$ (SRY) located on the Y chromosome. The result obtained from the real-time PCR was proven to be not significantly different from that obtained by flow cytometry reanalysis. However, since the quantification of both genes was done in separate tubes, imprecision in dispensing a small amount of the DNA template into each reaction tube may compound error in estimation of the sex ratio in the sample. Therefore, in this study, we aimed to develop a multiplex real-time PCR technique to simultaneously quantify both genes in a single tube to eliminate bias due to pipetting error and thus provide better estimation of the sperm sex ratio. Furthermore, combining the reaction into one tube is also more efficient in terms of the reagent used, and time and labor needed to conduct the test.

\section{MATERIALS AND METHODS}

\section{Primers and probes}

Primer and probe sequences for amplification and detection of the $\mathrm{X}$ chromosome-specific (PLP) and Y chromosome-specific (SRY) regions were as previously reported (Parati et al., 2006) (Table 1). The X- and YTaqman probes used in the multiplex PCR assay were labeled at the $5^{\prime}$ end with different fluorophores, i.e., CAL Fluor Orange 560 (Orange 560) for the X-specific probe and 6-Carboxyfluorescein (FAM) for the Y-specific probe. For the simplex PCR assay both probes were labeled with the same fluorophore, FAM. BHQ-1 quencher was incorporated at the $3^{\prime}$ end of all probes to permit fluorescent detection of specific product. All primers and probes were synthesized from Biosearch Technologies, Inc., Novato, CA, USA.

\section{Construction of reference DNA}

Two recombinant plasmids containing the amplified section of the PLP gene (p-PLP) and SRY sequence ( $p$ SRY) were constructed and used as reference templates for quantification of the sex-related DNA sequences. Each DNA fragment was amplified using primers as described in Table 1. The fragments were then purified and cloned into pDrive cloning vector using a QIAGEN PCR Cloning ${ }^{P l u s}$ Kit (Qiagen GmbH, Hilden, Germany) according to the manufacturer's instruction. The recombinant plasmids were extracted using a QIAprep Spin Miniprep Kit (Qiagen $\mathrm{GmbH}$, Germany). Plasmid concentrations were quantified spectrophotometrically at $260 \mathrm{~nm}$ using NanoDrop1000 spectrophotometer (Thermo Fisher Scientific, Inc., Wilmington, DE, USA). Both plasmids were mixed at a ratio of $1: 1$, and ten-fold serial dilutions ranging from $10 \mathrm{pg}$ to $1 \mathrm{fg}$ (approximately $2.33 \mathrm{E}+06$ to $2.33 \mathrm{E}+02$ plasmid copies) were used to construct a standard curve for quantification. Different ratios of p-PLP and p-SRY, i.e., 1:9 (X10), 1:1 (X50), and 9:1 (X90) at a final concentration of $100 \mathrm{fg}$ were used as known ratio templates to validate the method.

\section{Reaction conditions for real-time polymerase chain reaction}

The real-time PCR reaction condition was carried out as described by Parati et al. (2006). The $25 \mu \mathrm{L}$ reaction mixture of both simplex and multiplex real-time PCR contained $20 \mathrm{mM}$ Tris- $\mathrm{HCl}$ (pH 8.4), $50 \mathrm{mM} \mathrm{KCl,} 0.4 \mathrm{mM}$ dNTPs, $6 \mathrm{mM} \mathrm{MgCl}_{2}$ and $0.625 \mathrm{U}$ Platinum Taq DNA Polymerase (Life Technologies Co., Sao Paulo, Brazil). For the simplex PCR, a final concentration of $900 \mathrm{nM}$ of the primers and $200 \mathrm{nM}$ of the corresponding probes were added into two separate reaction tubes, one for PLP and one for SRY detection. For the multiplex PCR, both set of

Table 1. Primer and probe sequences

\begin{tabular}{llc}
\hline Primer/probe & \multicolumn{1}{c}{ Sequence $\left(5^{\prime} \rightarrow 3^{\prime}\right)$} & Product size $(\mathrm{bp})$ \\
\hline X chromosome-specific primers and probe & & 96 \\
PLP-Forward & GTTGTGTTAGTTTCTGCTGTACAATAAAGTG & \\
PLP-Reverse & GATGGCAGGTGAGGGTAGGA & \\
PLP-Probe & TGTATACACATAGCCCCTCCCTCTTGGA CC & 66 \\
Y chromosome-specific primers and probe & & \\
SRY-Forward & CCACGTCAAGCGACCCAT & \\
SRY-Reverse & AGAGCCACCTTTCGTCTTCG \\
SRY-Probe & AACGCCTTCATTGTGTGGTCTCGTGA & \\
\hline
\end{tabular}

PLP, bovine proteolipid protein gene; SRY, sex-determining region Y. 
primers were added into the same reaction tube at a final concentration of $400 \mathrm{nM}$ each, and $200 \mathrm{nM}$ of each probe (labeled with different fluorophores) were added into the same tube. An iCycler iQ real-time PCR detection system (Bio-Rad Laboratories, Inc., Hercules, CA, USA) was used for real-time PCR. The amplification conditions consisted of initial denaturation and enzyme activation at $95^{\circ} \mathrm{C}$ for 10 min, followed by 40 cycles of $95^{\circ} \mathrm{C}$ for $15 \mathrm{~s}$ and $60^{\circ} \mathrm{C}$ for $60 \mathrm{~s}$. The fluorescent signals were measured at the end of each amplification cycle. Analysis of the signals for determination of the threshold cycles $(\mathrm{Ct})$ was done using CFX manager software version 1.1 (Bio-Rad Laboratories, Inc., USA).

\section{Semen samples and DNA extraction}

The samples used in this study comprised two X-sorted semen samples, one Y-sorted semen sample, and three unsorted semen samples. The sorted semen samples containing spermatozoa of one sex at greater than $90 \%$ purity was purchased from Accelerated Genetics, Inc., Baraboo, WI, USA. Three unsorted semen were purchased from the Dairy Farming Promotion Organization of Thailand.

Each frozen semen sample was thawed and centrifuged at $500 \times \mathrm{g}$ for $10 \mathrm{~min}$ to collect the sperm pellet. The pellet was then washed with $500 \mu \mathrm{L}$ phosphate buffered saline, centrifuged at $500 \times \mathrm{g}$ for $5 \mathrm{~min}$, and the supernatant was discarded. Then, $10 \mu \mathrm{L}$ of $1 \mathrm{M}$ dithiothreitol, $10 \mu \mathrm{L}$ of $1 \mathrm{M}$ proteinase $\mathrm{K}$ and $100 \mu \mathrm{L}$ of $5 \%$ w/v chelex 100 resin (BioRad Laboratories, Inc., USA) were added to the sperm pellet. All reagents were mixed and incubated overnight at $56^{\circ} \mathrm{C}$. The cell debris was removed by centrifugation at $1,000 \times \mathrm{g}$ for $5 \mathrm{~min}$. Then, the crude DNA extract was further purified using a Wizard genomic DNA purification Kit (Promega, USA) following the manufacturer's protocol. The DNA concentration was measured spectrophotometrically at $260 \mathrm{~nm}$.

\section{Determination of sperm sex ratio by simplex real-time polymerase chain reaction}

For the simplex real-time PCR, the fluorescent signals from both $\mathrm{X}$ and $\mathrm{Y}$ amplifications were measured from the same channel (FAM). A single threshold line for determination of the $\mathrm{Ct}$ can be defined for both $\mathrm{X}$ and $\mathrm{Y}$ amplification. The threshold was set approximately in the middle of the exponential increase of the signal from positive samples. A standard curve showing relationship between $\mathrm{Ct}$ and copy number of the template for each sexspecific DNA was constructed using the reference plasmid DNA. Each sex-specific DNA from the test samples was then quantified using the corresponding standard curves, i.e., $\mathrm{X}$ from $\mathrm{X}$-standard curve and $\mathrm{Y}$ from $\mathrm{Y}$-standard curve. The percentage of $\mathrm{X}$ content $(\% \mathrm{X})$ and $\mathrm{Y}$ content $(\% \mathrm{Y})$ were estimated using the assumption that the sum of $\mathrm{X}$ and $\mathrm{Y}$ contents in each sample equals $100 \%$.

\section{Determination of sperm sex ratio by multiplex real-time polymerase chain reaction}

For the multiplex real-time PCR, two fluorescent signals were generated from each reaction tube, namely the Orange 560 signal from $X$ amplification and the FAM signal from $\mathrm{Y}$ amplification. A standard curve was constructed from each fluorescent channel and a threshold line of each fluorescent channel was defined using the same criteria as the simplex PCR. Quantification of X and $\mathrm{Y}$ contents as well as the sperm sex ratio were calculated in a similar fashion to those from the simplex PCR.

\section{Validation of the multiplex real-time polymerase chain reaction assay}

Sperm sex ratios presented as percentage of $\mathrm{X}$ chromosome-bearing spermatozoa $(\% \mathrm{X})$ obtained from the multiplex real-time PCR were compared with those obtained from the simplex real-time PCR. A total of nine samples used in this experiment included three samples of known \%X reference plasmids (X10\%, X50\%, and X90\%), two X-sorted semen samples, one Y-sorted semen sample, and three unsorted semen samples. Each sample was tested in triplicate independent PCRs. For each PCR, the samples were tested in duplicate reaction tubes and the average values were used to calculate the mean, standard deviation (SD), and $95 \%$ confidence interval $(95 \% \mathrm{CI})$ of the triplicate experiments. Validity of the multiplex real-time PCR assay was assessed by comparing the expected values (from the reference plasmids) to those obtained from the measurement. The assay was considered valid when all expected values fell within $95 \%$ CI of the measured values. Agreement between the sex ratio estimated from the multiplex real-time PCR and the simplex real-time PCR assay was assessed using a two-tailed paired t-test with significance level of $p<0.05$. The equality of variances between the methods was tested using Levene's test.

\section{RESULTS}

\section{Standard curves and amplification efficiency}

Standard curves showing relationship between the amount of template (copy number, $\log \mathrm{C}$ ) and $\mathrm{Ct}$ for each sex-related DNA from the simplex and multiplex assays are shown in Figure 1 and 2, respectively. All curves fitted to linear regression models with correlation coefficient (r) $>0.99$. For the simplex PCR, the general linear equations obtained from the three runs can be represented as: $\mathrm{Ct} \_\mathrm{X}=$ 35.40-3.34 $\log \mathrm{C}$ for $\mathrm{X}$ amplification and $\mathrm{Ct}$ _Y $=36.12$ $3.39 \log \mathrm{C}$ for $\mathrm{Y}$ amplification. For the multiplex PCR, the equations for $\mathrm{X}$ and $\mathrm{Y}$ were: $\mathrm{Ct} \_\mathrm{X}=40.56 .16-3.39 \log \mathrm{C}$ 


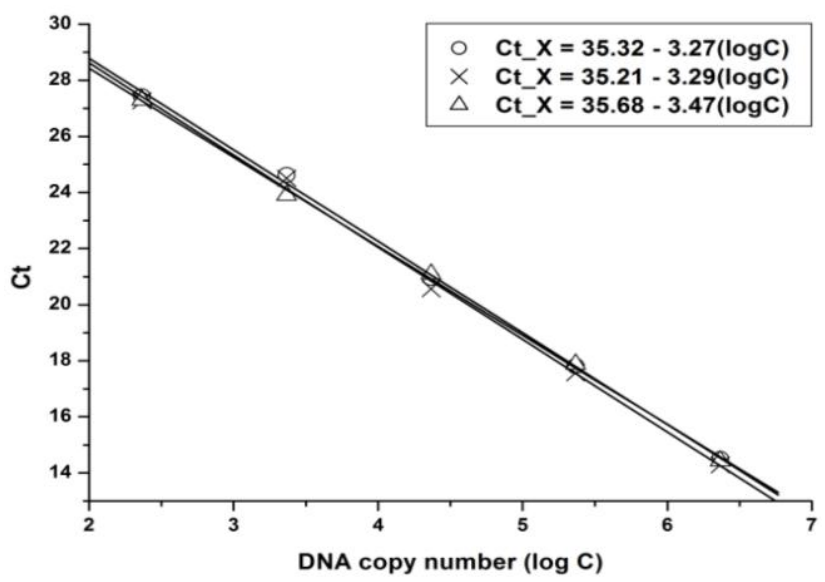

(A)

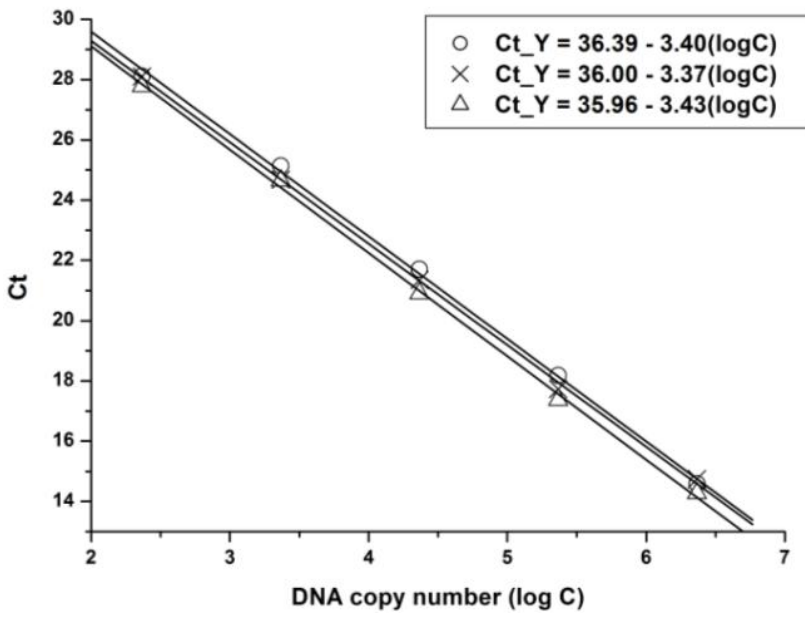

(B)

Figure 1. Standard curves and linear equations obtained from the simplex real-time polymerase chain reaction assay showing relationship between threshold cycle $(\mathrm{Ct})$ and DNA copy number $(\log \mathrm{C})$ from triplicate experiments. (A) $\mathrm{X}$ chromosome-specific amplification, (B) Y chromosome-specific amplification.

and Ct_Y $=41.01-3.35 \log C$, respectively.

The mean and SD of the slope from the simplex PCR assay were $-3.34 \pm 0.11$ and $-3.39 \pm 0.03$ which corresponded to the PCR amplification efficiency of $99 \%$ and $97 \%$ for X and $\mathrm{Y}$ amplification respectively; and from the multiplex $\mathrm{PCR}$, the slopes were $-3.39 \pm 0.05$ and $-3.35 \pm 0.03$ which corresponded to efficiencies of $97 \%$ and $99 \%$ for $\mathrm{X}$ and $\mathrm{Y}$ amplification, respectively.

Estimation of $\% \mathrm{X}$ in samples and comparison between the simplex and multiplex real-time polymerase chain reaction assay

The simplex PCR and multiplex PCR assays were used to measure ratios of the sex-specific sequences in the reference plasmids and semen samples. The results expressed as $\% \mathrm{X}$ in the samples are shown in Table 2. The expected values from the reference plasmid samples fell within the $95 \%$ CI of the measured values obtained from

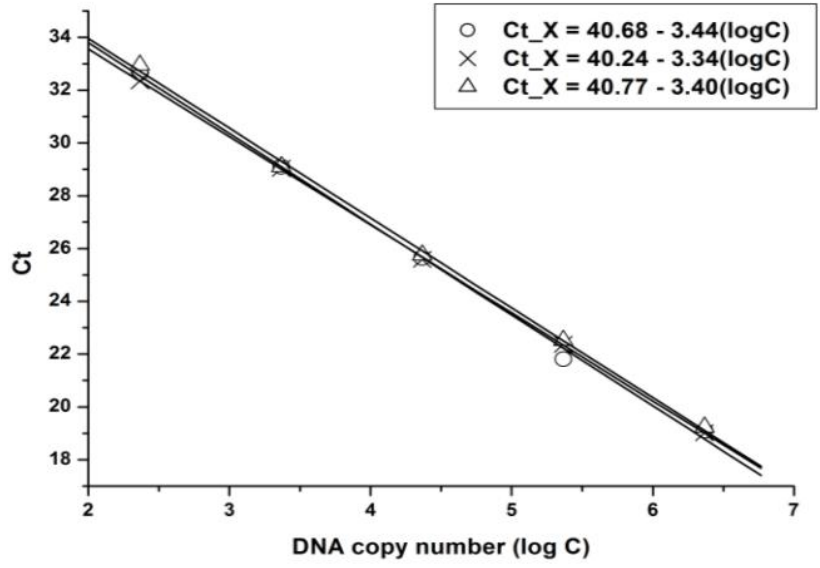

(A)

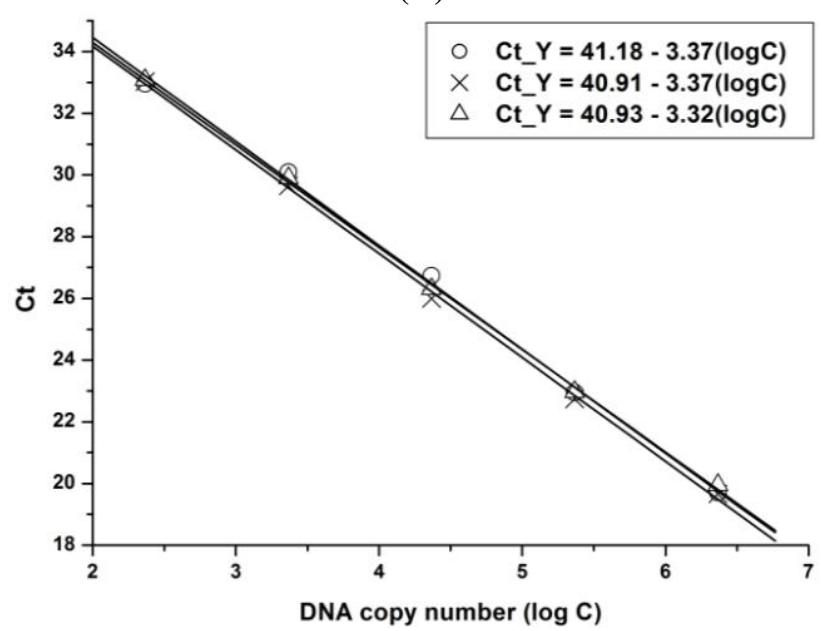

(B)

Figure 2. Standard curves and linear equations obtained from the multiplex real-time polymerase chain reaction assay showing relationship between threshold cycle $(\mathrm{Ct})$ and DNA copy number $(\log C)$ from triplicate experiments. (A) $\mathrm{X}$ chromosome-specific amplification, (B) Y chromosome-specific amplification.

the assays in all test ranges indicating validity of the assays for accurately assessing the sex ratio of the semen samples. Statistical analysis showed that the variances and mean of the sex ratio estimates obtained from the simplex and multiplex assays were not significantly different $(p>0.05)$ (Table 2).

\section{DISCUSSION}

In this study, we developed a multiplex real-time PCR technique as an alternative method for determination of sperm sex ratio in bovine semen samples. Analysis of the sperm sex ratio is important for selective reproduction of livestock by artificial insemination. This rapid and cost effective assay can also facilitate development of new sperm sex-sorting technologies. The assay simultaneously detects both $\mathrm{X}$ - and Y-specific determinants in a single reaction tube. Quantification of each sex-specific DNA was 
Table 2. Results of \%X quantified from the simplex real-time PCR and the multiplex real-time PCR

\begin{tabular}{|c|c|c|c|c|}
\hline \multirow{2}{*}{ No. } & \multirow{2}{*}{ Sample } & Simplex assay & Multiplex assay & \multirow{2}{*}{ p-value } \\
\hline & & Mean \pm SD $(95 \% \mathrm{CI})$ & Mean \pm SD $(95 \%$ CI $)$ & \\
\hline \multicolumn{5}{|c|}{ Reference plasmid } \\
\hline 1 & $\mathrm{X} 10 \%$ & $11.70 \pm 1.89(9.56-13.83)$ & $11.85 \pm 1.25(10.44-13.27)$ & 0.79 \\
\hline 2 & $\mathrm{X} 50 \%$ & $50.61 \pm 1.43(48.99-52.22)$ & $51.48 \pm 1.53(49.74-53.21)$ & 0.28 \\
\hline 3 & $\mathrm{X} 90 \%$ & $90.15 \pm 1.21(88.78-91.52)$ & $91.67 \pm 1.83(89.60-93.74)$ & 0.14 \\
\hline \multicolumn{5}{|c|}{ Semen sample } \\
\hline 4 & $\mathrm{X}$-sorted 1 & $92.28 \pm 2.27(89.72-94.84)$ & $93.03 \pm 2.13(90.63-95.44)$ & 0.42 \\
\hline 5 & X-sorted2 & $91.91 \pm 2.23(89.39-94.43)$ & $90.47 \pm 2.83(87.27-93.67)$ & 0.42 \\
\hline 6 & Y-sorted1 & $2.71 \pm 0.18(2.50-2.92)$ & $2.57 \pm 0.35(2.17-2.96)$ & 0.20 \\
\hline 7 & Unsorted1 & $50.34 \pm 2.44(47.58-53.11)$ & $49.44 \pm 2.17(46.99-51.89)$ & 0.20 \\
\hline 8 & Unsorted2 & $50.81 \pm 0.86(49.83-51.79)$ & $50.44 \pm 2.69(47.40-53.48)$ & 0.72 \\
\hline 9 & Unsorted3 & $50.23 \pm 1.97(48.00-52.45)$ & $49.44 \pm 1.76(47.44-51.43)$ & 0.40 \\
\hline
\end{tabular}

PCR, polymerase chain reaction; SD, standard deviation; CI, confidence interval.

done by the use of differently labeled Taqman probe, and comparing the $\mathrm{Ct}$ obtained from the sample to that obtained from the corresponding standard curve. The standard curve in this multiplex assay was also done in multiplex format, i.e., both $\mathrm{X}$ - and $\mathrm{Y}$ - specific recombinant plasmids were mixed at the ratio of 1:1 and a series of ten-fold dilutions of the known-quantity reference DNA was used to construct the standard curve for each sex-specific DNA. In addition, for reference DNA, genomic DNA may be used to construct the standard curve (Yun et al., 2006). Although the primers used in this multiplex assay were only half of the concentration used in the simplex assay, the amplification efficiencies were the same, i.e., they fell in the range between $97 \%$ to $99 \%$ efficiency for both assays. The multiplex assay was also proven to be as effective as the simplex assay in determination of the sperm sex ratio in both known-ratio reference plasmids and actual semen samples. For the sorted semen samples, the assay showed that they contained greater than $90 \%$ of the declared sexspecific DNA, which was in agreement with the semen specification guaranteed from the manufacturer $(>90 \%$ purity). For the unsorted semen in which the ratio of $1: 1$ was expected, the multiplex real-time PCR assay yielded approximately $50 \%$ of each sex-specific DNA, which is in agreement with the expected value. The multiplex real-time PCR technique as developed in this study yielded accurate assessment of the sperm sex ratio in both sorted and unsorted semen. Although the accurate assessment of the ratio can be obtained with other techniques such as flow cytometry analysis (Garner et al., 2013), individual spermPCR (Colley et al., 2008; Wang et al., 2011), simplex realtime PCR (Parati et al., 2006), the multiplex method as reported in this study is simpler, faster, and more costeffective to perform with only a single reaction tube required for each semen sample. In conclusion, the multiplex real-time PCR assay could be used as an alternative method to identify the sex ratio of the sperm in bovine semen.

\section{ACKNOWLEDGMENTS}

This work was funded by National Science and Technology Development Agency (NSTDA), Thailand. The first author was supported by Thailand Graduate Institute of Science and Technology scholarship (TG-22-10-51-005D) granted from NSTDA. We thank Dr. Philip Shaw for manuscript proofreading.

\section{REFERENCES}

Blecher, S. R., R. Howie, S. Li, J. Detmar, and L. M. Blahut. 1999. A new approach to immunological sexing of sperm. Theriogenology 52:1309-1321.

Colley, A., M. Buhr, and S. P. Golovan. 2008. Single bovine sperm sex typing by amelogenin nested PCR. Theriogenology 70:978-983.

Garner, D. L., K. M. Evans, and G. E. Seidel. 2013. Sex-sorting sperm using flow cytometry/cell sorting. Methods Mol. Biol. 927:279-295.

Garner, D. L. and G. E. Seidel Jr. 2003. Past, present and future perspectives on sexing sperm. Can. J. Anim. Sci. 83:375-384.

Habermann, F. A., A. Winter, I. Olsaker, P. Reichert, and R. Fries. 2005. Validation of sperm sexing in the cattle (Bos taurus) by dual colour fluorescence in situ hybridization. J. Anim. Breed. Genet. 122:22-27.

Hendriksen, P. J. M., M. Tieman, T. Van Der Lende, and L. A. Johnson. 1993. Binding of anti- $\mathrm{H}-\mathrm{Y}$ monoclonal antibodies to separated $\mathrm{X}$ and $\mathrm{Y}$ chromosome bearing porcine and bovine sperm. Mol. Reprod. Dev. 35:189-196.

Lee, J. H., J. H. Park, S.-H. Lee, C. S. Park, and D. I. Jin. 2004. Sexing using single blastomere derived from IVF bovine embryos by fluorescence in situ hybridization (FISH). Theriogenology 62:1452-1458.

Machado, G. M., J. O. Carvalho, E. S. Filho, E. S. Caixeta, M. M. Franco, R. Rumpf, and M. A. N. Dode. 2009. Effect of Percoll volume, duration and force of centrifugation, on in vitro production and sex ratio of bovine embryos. Theriogenology 
71:1289-1297.

Madrid-Bury, N., R. Fernández, A. Jiménez, S. Pérez-Garnelo, P. Nuno Moreira, B. Pintado, J. de la Fuente, and A. GutiérrezAdán. 2003. Effect of ejaculate, bull, and a double swim-up sperm processing method on sperm sex ratio. Zygote 11:229235.

Morrell, J. M., K. D. Keeler, D. E. Noakes, N. M. Mackenzie, and D. W. Dresser. 1988. Sexing of sperm by flow cytometry. Vet. Rec. 122:322-324.

Parati, K., G. Bongioni, R. Aleandri, and A. Galli. 2006. Sex ratio determination in bovine semen: A new approach by quantitative real time PCR. Theriogenology 66:2202-2209.

Piumi, F., D. Vaiman, E.-P. Cribiu, B. Guerin, and P. Humblot. 2001. Specific cytogenetic labeling of bovine spermatozoa bearing $\mathrm{X}$ or $\mathrm{Y}$ chromosomes using fluorescent in situ hybridization (FISH). Genet. Sel. Evol. 33:89-98.

Rens, W., F. Yang, G. Welch, S. Revell, P. C. O'Brien, N. Solanky, L. A. Johnson, and M. A. F. Smith. 2001. An XY paint set and sperm FISH protocol that can be used for validation of cattle sperm separation procedures. Reproduction 121:541-546.
Sang, L., W. C. Yang, L. Han, A. X. Liang, G. H. Hua, J. J. Xiong, L. J. Huo, and L. G. Yang. 2011. An immunological method to screen sex-specific proteins of bovine sperm. J. Dairy Sci. 94:2060-2070

Seidel Jr, G. E. 2007. Overview of sexing sperm. Theriogenology 68:443-446.

Wang, D., H. Zhu, J. Guo, B. Lin, L. Zhang, H. Hao, W. Du, and X. Zhao. 2011. A study of a method to assess the purity of sorted bovine semen using rapid single-sperm sexing PCR. J. Anim. Vet. Adv. 10:750-756.

Wolf, C. A., K. E. Brass, M. I. B. Rubin, S. E. Pozzobon, F. D. Mozzaquatro, and F. D. De La Corte. 2008. The effect of sperm selection by Percoll or swim-up on the sex ratio of in vitro produced bovine embryos. Anim. Reprod. 5:110-115.

Yun, J. J., L. E. Heisler, I. I. L. Hwang, O. Wilkins, S. K. Lau, M. Hyrcza, B. Jayabalasingham, J. Jin, J. McLaurin, M.-S. Tsao, and S. D. Der. 2006. Genomic DNA functions as a universal external standard in quantitative real-time PCR. Nucl. Acids Res. 34:e85. 